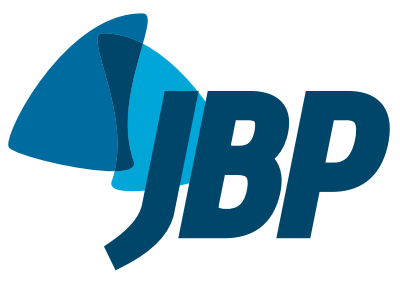

\title{
Asthma control, lung function, nutritional status, and health-related quality of life: differences between adult males and females with asthma
}

\author{
Gabriele Carra Forte ${ }^{1, a}$, Maria Luiza Hennemann²,b, Paulo de Tarso Roth Dalcinn,3,c
}

1. Programa de Pós-Graduação em Ciências Pneumológicas, Faculdade de Medicina, Universidade Federal do Rio Grande do Sul - UFRGS - Porto Alegre (RS) Brasil.

2. Departamento de Nutrição, Faculdade de Medicina, Universidade Federal do Rio Grande do Sul - UFRGS - Porto Alegre (RS) Brasil.

3. Serviço de Pneumologia, Hospital de Clínicas de Porto Alegre, Porto Alegre (RS) Brasil.

a. (iD) http://orcid.org/0000-0002-1480-8196

b. (iD) http://orcid.org/0000-0003-3603-4029

c. (iD http://orcid.org/0000-0002-9774-9135

Submitted: 19 June 2017.

Accepted: 30 October 2017

Study carried out at the Hospital de Clínicas de Porto Alegre - HCPA - Porto Alegre (RS) Brasil.

\begin{abstract}
Objective: To evaluate health-related quality of life in asthma patients treated at a referral center in southern Brazil, identifying differences between male and female patients, as well as to evaluate differences between the males and females in terms of asthma control, lung function, and nutritional status. Methods: This was a cross-sectional study involving patients $\geq 18$ years of age treated at an asthma outpatient clinic. We evaluated clinical parameters, lung function, nutritional status, and quality of life. Results: A total of 198 patients completed the study. The mean age was $56.2 \pm 14.8$ years, and $81.8 \%$ were female. The proportion of patients with uncontrolled asthma was higher among females than among males $(63.0 \%$ vs. $44.4 \% ; p=0.041)$. The body mass index (BMI) and percentage of body fat were higher in females than in males $\left(30.2 \pm 5.8 \mathrm{~kg} / \mathrm{m}^{2} \mathrm{vs}\right.$. $26.9 \pm 4.5 \mathrm{~kg} / \mathrm{m}^{2}$ and $37.4 \pm 6.4 \%$ vs. $26.5 \pm 7.4 \% ; p=0.002$ and $p<0.001$, respectively). Quality of life was lower in females than in males in the following domains: symptoms ( $3.8 \pm 1.5$ vs. $4.6 \pm 1.7 ; p=0.006)$; activity limitation ( $3.6 \pm 1.3$ vs. $4.4 \pm 1.5 ; p=0.001)$; emotional function $(3.6 \pm 1.9$ vs. $4.5 \pm 1.7 ; p=0.014)$; and environmental stimuli $(3.2 \pm$ 1.6 vs. $4.3 \pm 1.9 ; p=0.001)$. Conclusions: Male asthma patients appear to fare better than do female asthma patients in terms of health-related quality of life, asthma control, $\mathrm{BMI}$, percentage of body fat, and comorbidities.
\end{abstract}

Keywords: Asthma; Nutritional status; Quality of life; Adult.

\section{INTRODUCTION}

Asthma is a chronic inflammatory disease of the airways characterized by respiratory symptoms such as wheeze, shortness of breath, chest tightness, and cough that vary over time and in intensity, as well as by variable expiratory airflow limitation and airway hyperresponsiveness to direct or indirect stimuli. It is a prevalent disease that impairs quality of life, being a major public health problem. Asthma affects approximately $10 \%$ of adults worldwide.(1) The prevalence of asthma follows a characteristic age- and gender-related pattern, being highest during childhood and predominantly affecting males. (2) After puberty, the prevalence of asthma is higher in females than in males. $(2,3)$

Many mechanisms are involved in the clinical expression of asthma, including sex hormones, airway caliber, obesity, type of exposure, and age at onset. ${ }^{(4,5)}$ Although males and females with asthma share the common clinical features of the disease, the natural course of asthma differs between the genders. Takeda et al. ${ }^{(6)}$ suggested that sex hormones and gender differences are involved in cellular functions in airway remodeling. Several studies have reported that asthma is more prevalent and more severe in adult females. In a cross-sectional study, asthma severity was found to have increased with the body mass index (BMI), although only in females; however, the reason for this has yet to be explained. ${ }^{(7-9)}$ Zillmer et al. ${ }^{(10)}$ noted that poorly controlled asthma and respiratory symptoms were more common in females than in males. In addition, self-reported quality of life is often worse in females than in males, probably due to dyspnea that is more severe and increased drug use. ${ }^{(11)}$ As a result of this clinical heterogeneity, treatment approaches need to be individualized and modified in order to maintain adequate symptom and disease control over time. ${ }^{(12)}$

Although several studies have examined gender differences in asthma patients, few have investigated the impact of asthma on health-related quality of life and nutritional status. ${ }^{(11,13)}$ In addition, there are differences and regional disparities in disease control and clinical expression among asthma patients. ${ }^{(14)}$ Therefore, it is important to evaluate gender differences in different populations of adults with asthma.

The primary objective of the present study was to evaluate differences in health-related quality of life between adult males and females with asthma treated at a referral center in southern Brazil. A secondary objective was to

\section{Correspondence to:}

Gabriele Carra Forte. Rua General Lima e Silva, 148/405, Bloco A, Centro Histórico, CEP 90050-100, Porto Alegre, RS, Brasil.

Tel.: 5551 8272-4010. E-mail: gabicarraforte@yahoo.com.br

Financial support: This study received financial support from the Fundo de Incentivo à Pesquisa do Hospital de Clínicas de Porto Alegre (FIPE-HCPA

Research Incentive Fund of the Porto Alegre Hospital de Clínicas), the Coordenação de Aperfeiçoamento de Pessoal de Nive/ Superior (CAPES, Office for the Advancement of Higher Education), and the Brazilian Conselho Nacional de Desenvolvimento Científico e Tecnológico (CNPq, National Council for Scientific and Technological Development). Gabriele Carra Forte and Maria Luiza Hennemann are recipients of grants from CAPES/CNPq. 
evaluate differences in asthma control, lung function, and nutritional status between those two groups.

\section{METHODS}

In a cross-sectional study of prospectively collected data, we assessed consecutive adult patients with asthma recruited from among those treated at a referral center for asthma in southern Brazil. The study protocol was approved by the Research Ethics Committee of the Hospital de Clínicas de Porto Alegre (HCPA), located in the city of Porto Alegre, Brazil (Protocol no. 12.0103), and written informed consent was obtained from all patients.

Patients were recruited from among those treated at the HCPA asthma outpatient clinic, located in the city of Porto Alegre, Brazil. The study included patients who were 18 years of age or older and who had physician-diagnosed asthma. The diagnosis of asthma was confirmed by a member of the research team on the basis of the following criteria: symptoms of asthma, accompanied by reversible airflow obstruction (an increase of at least $12 \%$ and $200 \mathrm{~mL}$ in $\mathrm{FEV}_{1}$ after administration of a short-acting $\beta_{2}$ agonist) or bronchial hyperresponsiveness to a bronchoconstricting agent (methacholine).(1)

The exclusion criteria were as follows: chronic lung diseases other than asthma (such as COPD and bronchiectasis); lobectomy; abnormal chest X-ray findings; pregnancy; and current or past smoking (a smoking history of more than 10 pack-years).

During an outpatient visit, participants underwent a comprehensive clinical evaluation and completed questionnaires regarding the following: medical history; socioeconomic status; demographic characteristics; smoking history; chronic comorbidities; medication use; menopause (no menstruation in the last 12 months); nutritional status; asthma severity; level of asthma control; and health-related quality of life.

Nutritional status was assessed by the body mass index (BMI), which was calculated by the formula weight/height ${ }^{2}\left(\mathrm{~kg} / \mathrm{m}^{2}\right)$. On the basis of their BMI, participants were stratified into the following categories ${ }^{(15)}$ : underweight $\left(<18.5 \mathrm{~kg} / \mathrm{m}^{2}\right)$; normal weight $\left(18.5-24.9 \mathrm{~kg} / \mathrm{m}^{2}\right)$; overweight $(25-29.9 \mathrm{~kg} /$ $\left.\mathrm{m}^{2}\right)$; and obese $\left(\geq 30 \mathrm{~kg} / \mathrm{m}^{2}\right)$. Bioelectrical impedance analysis was used in order to assess body composition (i.e., the proportions of muscle, fat, and water).(16)

Asthma severity was determined in accordance with the Global Initiative for Asthma (GINA) guidelines, ${ }^{(1)}$ patients being classified as having mild intermittent asthma, mild persistent asthma, moderate persistent asthma, or severe persistent asthma on the basis of daily medication use. The level of asthma control was also determined in accordance with the GINA guidelines, ${ }^{(1)}$ patients being classified as having well-controlled, partly controlled, or uncontrolled asthma on the basis of the following: frequency of daytime and nighttime symptoms; rescue medication use; limitation of daily physical activity; and number of exacerbations in the last 4 weeks.

Spirometry was performed with a v4.31a spirometer (Jaeger, Würzburg, Germany). FVC, $\mathrm{FEV}_{1}$, and the $\mathrm{FEV}_{1} /$ FVC ratio were measured three times, the best of the three measurements being recorded. All pulmonary function test results were expressed as a percentage of the predicted values for age, height, and gender. ${ }^{(17)}$

Quality of life was assessed by the Asthma Quality of Life Questionnaire (AQLQ), ${ }^{(18)}$ which had previously been translated to Portuguese and validated for use in Brazil. ${ }^{(19)}$ The AQLQ is divided into four domains: symptoms; activity limitation; emotional function; and environmental stimuli. Each domain is scored from 1 to 7 , a score of 1 indicating maximum impairment and a score of 7 indicating no impairment.

Sample size calculation was based on a study by Dalcin et al.(14) For a proportion of $60 \%$ of female patients with uncontrolled asthma, a proportion of $45 \%$ of male patients with uncontrolled asthma, a total width of 0.15 , a type I error of 0.05 (two-sided), and a type II error of 0.20 (or a study power of 0.80 ), the required sample size was calculated to be 186 .

Statistical analysis of the data was performed with the IBM SPSS Statistics software package, version 20.0 (IBM Corporation, Armonk, NY, USA). Quantitative data were expressed as mean \pm standard deviation or median (interquartile range), and qualitative data were expressed as n (\%). Categorical variables were compared by the chi-square test with adjusted standardized residuals, Yates' correction or Fisher's exact test being used as appropriate. For continuous variables, the Student's t-test or the Mann-Whitney $U$ test was used for between-group comparisons. All statistical tests were two-tailed, and the level of significance was set at $p<0.05$.

\section{RESULTS}

Between March and December of 2013, we evaluated 344 patients with asthma. Of those, 75 declined to participate, 53 were excluded because they had chronic lung diseases other than asthma, 8 were excluded because they were smokers or former smokers (with a smoking history of more than 10 pack-years), and 10 were excluded because they failed to have all of the required assessments performed. Therefore, the final sample consisted of 198 patients.

The general characteristics of the participating patients are presented in Table 1. Of the 198 participants, $162(81.8 \%)$ were female. The mean age was 56.2 \pm 14.8 years. With regard to the severity of asthma, 144 patients $(72.2 \%)$ had severe persistent asthma, $31(15.7 \%)$ had moderate persistent asthma, and 23 $(11.6 \%)$ had mild persistent asthma. With regard to the level of asthma control, 118 patients $(59.6 \%)$ had uncontrolled asthma, $28(14.1 \%)$ had partly controlled asthma, and $52(26.3 \%)$ had well-controlled asthma. The mean BMI was $29.6 \pm 5.7 \mathrm{~kg} / \mathrm{m}^{2}, 83$ patients (41.9\%) being classified as obese, $72(36.4 \%)$ being 
Table 1. General characteristics of the patients with asthma in the present study. ${ }^{a}$

\begin{tabular}{|c|c|}
\hline Variable & $N=198$ \\
\hline \multicolumn{2}{|l|}{ Gender } \\
\hline Female & $162(81.8)$ \\
\hline Male & $36(18.2)$ \\
\hline Age, years ${ }^{\mathrm{b}}$ & $56.2 \pm 14.8$ \\
\hline Menopause & $115(71)$ \\
\hline \multicolumn{2}{|l|}{ Race } \\
\hline White & $150(75.3)$ \\
\hline Non-White & $48(24.2)$ \\
\hline Age at diagnosis, years ${ }^{c}$ & $20.5(44)$ \\
\hline \multicolumn{2}{|l|}{ Smoking status } \\
\hline Never smoker & $138(69.7)$ \\
\hline Former smoker & $60(30.3)$ \\
\hline \multicolumn{2}{|c|}{ GINA asthma severity classification } \\
\hline Mild & $23(11.6)$ \\
\hline Moderate & $31(15.7)$ \\
\hline Severe & $144(72.7)$ \\
\hline \multicolumn{2}{|l|}{ GINA asthma control } \\
\hline Well-controlled & $52(26.3)$ \\
\hline Partly controlled & $28(14.1)$ \\
\hline Uncontrolled & $118(59.6)$ \\
\hline $\mathrm{BMI}, \mathrm{kg} / \mathrm{m}^{2 \mathrm{~b}}$ & $29.6 \pm 5.7$ \\
\hline \multicolumn{2}{|l|}{ Nutritional status } \\
\hline Normal weight & $43(21.7)$ \\
\hline Overweight & $72(36.4)$ \\
\hline Obesity & 83 (41.9) \\
\hline \multicolumn{2}{|c|}{ Pre-bronchodilator lung function ${ }^{\mathrm{b}}$} \\
\hline FVC, L & $2.5 \pm 0.9$ \\
\hline FVC, \% predicted & $81.2 \pm 21.3$ \\
\hline $\mathrm{FEV}_{1}, \mathrm{~L}$ & $1.7 \pm 0.7$ \\
\hline $\mathrm{FEV}_{1}, \%$ predicted & $68.2 \pm 22.2$ \\
\hline FEV /FVC, \% predicted & $82.1 \pm 13.0$ \\
\hline
\end{tabular}

GINA: Global Initiative for Asthma; and BMI: body mass index. ${ }^{a}$ Data expressed as $\mathrm{n}(\%)$, except where otherwise indicated. 'Data expressed as mean \pm SD. cData expressed as median (interquartile range).

classified as overweight, and 43 (21.7\%) being classified as normal weight.

Table 2 shows a comparison between the genders in terms of clinical characteristics, health-related quality of life, level of asthma control, lung function, and nutritional status. The prevalence of White patients was higher among males than among females $(91.7 \% \mathrm{vs}$ $72.0 \% ; p=0.024)$. Quality of life was lower in females than in males in all four AQLQ domains: symptoms (3.8 \pm 1.5 vs. $4.6 \pm 1.7 ; p=0.006)$; activity limitation ( $3.6 \pm 1.3$ vs. $4.4 \pm 1.5 ; p=0.001)$; emotional function ( $3.6 \pm 1.9$ vs. $4.5 \pm 1.7 ; p=0.014$ ); and environmental stimuli ( $3.2 \pm 1.6$ vs. $4.3 \pm 1.9 ; p=$ $0.001)$. The proportion of patients with uncontrolled asthma was higher among females than among males (63.0\% vs. $44.4 \%$; $p=0.041)$. In addition, the BMI and percentage of body fat were higher in females than in males $\left(30.2 \pm 5.8 \mathrm{~kg} / \mathrm{m}^{2}\right.$ and $37.4 \pm 6.4 \%$ vs. $26.9 \pm 4.5 \mathrm{~kg} / \mathrm{m}^{2}$ and $26.5 \pm 7.4 \% ; p=0.002$ and $p<0.001$, respectively). Chronic comorbidities were more commonly reported by females than by males (68.5\% vs. $38.9 \% ; p=0.001)$, as were cardiovascular comorbidities ( $58.0 \%$ vs. $36.1 \%$; $p=0.028)$. There were no significant differences between the genders regarding age $(p=0.805)$, asthma severity $(p=$ $0.401)$, percent predicted FVC $(p=0.078)$, or percent predicted $\mathrm{FEV}_{1}(p=0.085)$. In addition, there was no association between menopause and the study outcomes.

\section{DISCUSSION}

In the present study, females predominated among adult patients with asthma treated at a referral outpatient clinic in southern Brazil. Health-related quality of life was found to be lower in females than in males in all four AQLQ domains. In addition, the proportion of patients with uncontrolled asthma was higher among females than among males, as were the BMI and percentage of body fat. Furthermore, comorbidities were more commonly reported by females than by males.

The high prevalence of asthma in adult females in the present study is consistent with the literature. ${ }^{(20-22)}$ Zillmer et al.(10) interviewed 400 asthma patients in four Brazilian cities and reported that 272 (68\%) were female. Dursun et al. ${ }^{(23)}$ studied 242 adult patients with asthma in Turkey and reported that $77.3 \%$ were female. Schatz \& Camargo ${ }^{(24)}$ used computerized data from Kaiser-Permanente Southern California in order to identify patients with asthma. Among the 60,694 asthma patients, the female-male prevalence ratio was approximately 65:35 in the 23- to 64-year age bracket. Previous studies conducted at our institution in different settings and involving different samples of adults have shown a high (68.6-75\%) prevalence of females seeking hospital treatment for asthma. $(7,25,26)$ There is compelling evidence that sex hormones are major determinants of at least these biological differences in asthma prevalence. ${ }^{(20)}$ It has been reported that estrogen receptor 1 polymorphisms are associated with bronchial hyperresponsiveness and lung function decline, especially in females with asthma. ${ }^{(4)}$

The overall health-related quality of life in our sample was moderate, AQLQ scores being significantly lower among females than among males. Other studies have shown that health-related quality of life is worse in female asthma patients than in male asthma patients. ${ }^{(11,27,28)}$ In a cross-sectional study, Lisspers et al. (29) investigated 1,226 patients in a primary care setting and 499 patients in a secondary care setting. They concluded that quality of life and the level of asthma control were lower in young females than in young males, although no such differences were found between older females and older males. Female sex hormones could be an important factor affecting these outcomes. Correia de Sousa et al. ${ }^{(30)}$ found that females were 3.8 times more likely to have poorer quality of life than were males. This finding was associated with 
Table 2. Comparison between the genders in terms of clinical characteristics, level of asthma control, lung function, nutritional status, and health-related quality of life. ${ }^{\mathrm{a}}$

\begin{tabular}{|c|c|c|c|}
\hline Variable & $\begin{array}{c}\text { Females } \\
(n=162)\end{array}$ & $\begin{array}{c}\text { Males } \\
(n=36)\end{array}$ & p* \\
\hline Age, years $^{b}$ & $56.3 \pm 14.2$ & $55.7 \pm 17.8$ & 0.805 \\
\hline \multicolumn{4}{|l|}{ Race } \\
\hline White & $116(72)$ & $33(91.7)$ & \multirow{2}{*}{0.024} \\
\hline Non-White & $45(28)$ & $3(8.3)$ & \\
\hline Age at diagnosis, years ${ }^{c}$ & $18(43)$ & $29(44)$ & 0.021 \\
\hline \multicolumn{4}{|l|}{ Smoking status } \\
\hline Never smoker & $116(71.6)$ & $22(61.1)$ & \multirow[t]{2}{*}{0.150} \\
\hline Former smoker & $46(28.4)$ & $14(38.9)$ & \\
\hline \multicolumn{4}{|l|}{ GINA asthma severity classification } \\
\hline Mild & $21(13)$ & $2(5.6)$ & \multirow{3}{*}{0.401} \\
\hline Moderate & $24(14.8)$ & $7(19.4)$ & \\
\hline Severe & $117(72.2)$ & $27(75)$ & \\
\hline \multicolumn{4}{|l|}{ GINA asthma control } \\
\hline Well-controlled/partly controlled & $60(37.0)$ & $20(55.6)$ & \multirow{2}{*}{0.041} \\
\hline Uncontrolled & $102(63.0)$ & $16(44.4)$ & \\
\hline \multicolumn{4}{|l|}{ Nutritional markers ${ }^{\mathrm{b}}$} \\
\hline $\mathrm{BMI}, \mathrm{kg} / \mathrm{m}^{2}$ & $30.2 \pm 5.8$ & $26.9 \pm 4.5$ & 0.002 \\
\hline Body fat, $\%$ & $37.4 \pm 6.4$ & $26.5 \pm 7.4$ & $<0.001$ \\
\hline Comorbidities & $111(68.5)$ & $14(38.9)$ & 0.001 \\
\hline Cardiovascular comorbidities & $94(58.0)$ & $13(36.1)$ & 0.028 \\
\hline \multicolumn{4}{|l|}{ Pre-bronchodilator lung function ${ }^{\mathrm{b}}$} \\
\hline FVC, L & $2.3 \pm 0.7$ & $3.3 \pm 1.0$ & $<0.001$ \\
\hline FVC, \% predicted & $83.2 \pm 20.9$ & $76.3 \pm 22.0$ & 0.078 \\
\hline $\mathrm{FEV}_{1}, \mathrm{~L}$ & $1.6 \pm 0.6$ & $2.2 \pm 0.9$ & $<0.001$ \\
\hline $\mathrm{FEV}_{1}, \%$ predicted & $69.5 \pm 21.7$ & $62.4 \pm 23.9$ & 0.085 \\
\hline $\mathrm{FEV}_{1} / \mathrm{FVC}, \%$ predicted & $82.4 \pm 12.3$ & $80.8 \pm 15.9$ & 0.492 \\
\hline \multicolumn{4}{|l|}{ Quality of life ${ }^{b}$} \\
\hline Symptoms & $3.8 \pm 1.5$ & $4.6 \pm 1.7$ & 0.006 \\
\hline Activity limitation & $3.6 \pm 1.3$ & $4.4 \pm 1.5$ & 0.001 \\
\hline Emotional function & $3.6 \pm 1.9$ & $4.5 \pm 1.7$ & 0.014 \\
\hline Environmental stimuli & $3.2 \pm 1.6$ & $4.3 \pm 1.9$ & 0.001 \\
\hline
\end{tabular}

GINA: Global Initiative for Asthma; and BMI: body mass index. *Values of $p<0.05$ were considered significant. ${ }^{a}$ Data expressed as $\mathrm{n}(\%)$, except where otherwise indicated. ${ }^{b}$ Data expressed as mean $\pm \mathrm{SD}$. 'Data expressed as median (interquartile range).

higher rates of anxiety and depression in the female population. ${ }^{(13)}$ A possible explanation for this finding is that being overweight and having uncontrolled asthma is more common in females than in males. These findings are consistent with those of Xu et al., (31) who investigated the association between obesity and asthma outcomes in older adults.

In the present study, asthma severity was assessed by the GINA classification system on the basis of daily medication use, ${ }^{(1)}$ meaning that although effective therapy was able to control the disease, it did not interfere with the classification of disease severity. The proportion of patients with severe persistent asthma was high in the present study (i.e., 72.7\%). However, asthma severity and lung function (as assessed by percent predicted FVC and $\mathrm{FEV}_{1}$ ) did not differ between males and females. In contrast, Carvalho-Pinto et al. ${ }^{(22)}$ reported that the female predominance in their group of patients suggested that severe asthma was a gender-related disease.

Asthma control, which is defined as the extent to which the various manifestations of asthma are reduced or removed by treatment, is increasingly receiving attention not only in clinical trials but also in clinical practice. ${ }^{(21)}$ In the present study, the proportion of patients with uncontrolled asthma was higher among females than among males. Previous studies have shown a lower level of asthma control in females than in males, despite a higher use of inhaled corticosteroids and more frequent visits to an asthma treatment center among the former. ${ }^{(22,32)}$ It has also been reported that females are 3.2 times more likely to have uncontrolled asthma than are males. ${ }^{(30)}$ Poor asthma control in females might also be related to being overweight. Although mechanisms linking both conditions are still poorly understood, there is evidence that obesity impairs clinical control. ${ }^{(33)}$ Although clinical observations indicate that 
menopause is generally associated with weight gain exacerbation of asthma, and, consequently, worsening of asthma control, ${ }^{(34)}$ we found no association between menopause and the study outcomes.

Obesity is defined as an increase in body weight resulting from excess body fat. Previous studies have shown a high prevalence of obesity among asthma patients treated at an asthma outpatient clinic, $(7,35,36)$ a finding that is consistent with those of the present study, in which the BMI and percentage of body fat were found to be higher in females than in males. Of the patients in our sample, $155(78.3 \%)$ were overweight (i.e., had a BMI $\geq 25 \mathrm{~kg} / \mathrm{m}^{2}$ ), and 133 $(82 \%)$ were female. A high BMI has been associated with poor asthma control and quality of life. ${ }^{(22,33)}$ Another finding that might have been influenced by excess weight and body fat is lung function. Dunn et al. ${ }^{(37)}$ found that $F E V_{1}$ values were significantly higher in females than in males $(84.5 \%$ vs. $81.1 \%$; $p<$ $0.001)$. However, in the present study, no significant differences were found between the genders regarding lung function parameters (i.e., percent predicted FVC, $\mathrm{FEV}_{1}$, and $\mathrm{FEV}_{1} / \mathrm{FVC}$ ).

Asthma is often associated with various comorbidities, the most common being rhinitis, sinusitis, gastroesophageal reflux disease, obstructive sleep apnea, hormonal disorders, and psychopathologies. ${ }^{(38)}$ These conditions might share a common pathophysiological mechanism with asthma, influence asthma control, or be more prevalent in asthma patients, having, however, no obvious influence on asthma. (38) Peters et al. ${ }^{(39)}$ reported that comorbidities were significantly associated with uncontrolled asthma. In the present study, chronic and cardiovascular comorbidities were more commonly reported by females than by males. Cazzola et al. ${ }^{(40)}$ reported that being female slightly increased the association of all cardiovascular diseases with asthma. They also reported that the association of asthma with diabetes mellitus, dyslipidemia, osteoporosis, depression, and psychiatric disorders was stronger in females than in males.

The present study has potential limitations. Given that it was a cross-sectional study, it was impossible to establish a temporal sequence between gender and the factors studied. In addition, this was a single-center study, and the sample size was small. Furthermore, the study population was selected from among patients treated at a referral center and was probably biased toward those with disease that is more severe.

In summary, health-related quality of life is lower in adult females with asthma than in adult males with asthma, as evidenced by lower scores in all four AQLQ domains. In addition, the proportion of patients with uncontrolled asthma is higher among females than among males, as are the BMI, percentage of body fat, and reported rates of comorbidities.

\section{REFERENCES}

1. Global Initiative for Asthma (GINA). Global strategy for asthma management and prevention 2016. Bethesda: GINA; 2016

2. Gerritsen J. Airway responsiveness in teenagers is becoming sexier. Am J Respir Crit Care Med. 2008;178(4):321-2. https://doi. org/10.1164/rccm.200805-736ED

3. Farha S, Asosingh K, Laskowski D, Hammel J, Dweik RA, Wiedemann $H P$, et al. Effects of the menstrual cycle on lung function variables in women with asthma. Am J Respir Crit Care Med. 2009;180(4):30410. https://doi.org/10.1164/rccm.200904-04970C

4. Melgert BN, Ray A, Hylkema MN, Timens W, Postma DS. Are there reasons why adult asthma is more common in females? Curr Allergy Asthma Rep. 2007;7(2):143-50. https://doi.org/10.1007/s11882-0070012-4

5. Vink NM, Postma DS, Schouten JP, Rosmalen JG, Boezen HM Gender differences in asthma development and remission during transition through puberty: the TRacking Adolescents' Individual Lives Survey (TRAILS) study. J Allergy Clin Immunol. 2010;126(3):498-504 e1-6

6. Takeda M, Tanabe M, Ito W, Ueki S, Konnno Y, Chihara M, et al Gender difference in allergic airway remodelling and immunoglobulin production in mouse model of asthma. Respirology. 2013;18(5):797 806. https://doi.org/10.1111/resp.12078

7. Forte GC, Grutcki DM, Menegotto SM, Pereira RP, Dalcin Pde $\mathrm{T}$. Prevalence of obesity in asthma and its relations with asthma severity and control. Rev Assoc Med Bras (1992). 2013;59(6):594-9. https://doi.org/10.1590/S0104-42302013000600014

8. Delgado J, Barranco P, Quirce S. Obesity and asthma. J Investig Allergol Clin Immunol. 2008;18(6):420-5

9. Ali Z, Ulrik CS. Obesity and asthma: a coincidence or a causal relationship? A systematic review. Respir Med. 2013;107(9):1287300. https://doi.org/10.1016/j.rmed.2013.03.019

10. Zillmer LR, Gazzotti MR, Nascimento OA, Montealegre F, Fish J, Jardim JR. Gender differences in the perception of asthma and respiratory symptoms in a population sample of asthma patients in four Brazilian cities. J Bras Pneumol. 2014;40(6):591-8. https://doi org/10.1590/S1806-37132014000600002
11. Wijnhoven HA, Kriegsman DM, Snoek FJ, Hesselink AE, de Haan M. Gender differences in health-related quality of life among asthma patients. The J Asthma. 2003:40(2):189-99. https://doi.org/10.1081/ JAS-120017990

12. Lemanske RF Jr, Busse WW. Asthma: clinical expression and molecular mechanisms. J Allergy Clin Immunol. 2010;125(2 Supp 2):S95-102. https://doi.org/10.1016/j.jaci.2009.10.047

13. Belloch A, Perpi-á M, Martínez-Moragón E, de Diego A, MartínezFrancés $M$. Gender differences in health-related quality of life among patients with asthma. J Asthma. 2003;40(8):945-53. https://doi. org/10.1081/JAS-120024595

14. Dalcin PT, Menegotto DM, Zanonato A, Franciscatto L, Soliman F Figueiredo $\mathrm{M}$, et al. Factors associated with uncontrolled asthma in Porto Alegre, Brazil. Braz J Med Biol Res. 2009;42(11):1097-103. https://doi.org/10.1590/S0100-879X2009005000035

15. World Health Organization. Obesity: preventing and managing the global epidemic. Report of a World Health Organization Consultation. Geneva: World Health Organization; 2000. p. 256

16. Pollock ML, Wilmore JH. Exercícios na Saúde e na Doença: Avaliação e Prescrição para Prevenção e Reabilitação. 2nd ed. Rio de Janeiro: MEDSI; 1993

17. Pereira CA, Barreto SP, Simões JG, Pereira FW, Gerstler JG Nakatani J. Valores de referência para espirometria em uma amostra da população brasileira adulta. J Pneumol. 1992;18(1):10-22.

18. Juniper EF. Health-related quality of life in asthma. Curr Opin Pulm Med. 2003;9 Suppl 1:S8-10. https://doi.org/10.1097/00063198200304001-00003

19. Silva LM, Silva LL. Validação do questionário de qualidade de vida em asma (Juniper) para o português brasileiro. Rev AMRGS 2007;51(1):31-7

20. Dijkstra A, Howard TD, Vonk JM, Ampleford EJ, Lange LA, Bleecker ER, Meyers DA, et al. Estrogen receptor 1 polymorphisms are associated with airway hyperresponsiveness and lung function decline, particularly in female subjects with asthma. J Allergy Clin Immunol. 2006;117(3):604-11. https://doi.org/10.1016/j. jaci.2005.11.023 
21. Reddel HK, Taylor DR, Bateman ED, Boulet LP, Boushey HA Busse WW, et al. An official American Thoracic Society/European Respiratory Society statement: asthma control and exacerbations: standardizing endpoints for clinical asthma trials and clinical practice. Am J Respir Crit Care Med. 2009;180(1):59-99. https://doi. org/10.1164/rccm.200801-060ST

22. de Carvalho-Pinto RM, Cukier A, Angelini L, Antonangelo L, Mauad T, Dolhnikoff $\mathrm{M}$, et al. Clinical characteristics and possible phenotypes of an adult severe asthma population. Respir Med. 2012;106(1):47 56. https://doi.org/10.1016/j.rmed.2011.08.013

23. Dursun AB, Kurt OK, Bayiz H, Ozkan E, Cakaloglu A, Karasoy D. Does gender affect asthma control in adult asthmatics? Chron Respir Dis. 2014;11(2):83-7. https://doi.org/10.1177/1479972314527468

24. Schatz M, Camargo CA Jr. The relationship of sex to asthma prevalence, health care utilization, and medications in a large managed care organization. Ann Allergy Asthma Immunol. 2003:91(6):553-8. https://doi.org/10.1016/S1081-1206(10)61533-5

25. Dalcin Pde T, da Rocha PM, Franciscatto E, Kang SH, Menegotto DM, Polanczyk CA, et al. Effect of clinical pathways on the management of acute asthma in the emergency department: five years of evaluation. J Asthma. 2007;44(4):273-9. https://doi org/10.1080/02770900701247020

26. Piovesan DM, Menegotto DM, Kang S, Franciscatto E, Millan T Hoffmann $\mathrm{C}$, et al. Early prognosis of acute asthma in the emergency room. J Bras Pneumol. 2006;32(1):1-9. https://doi.org/10.1590/ S1806-37132006000100004

27. Trawick DR, Holm C, Wirth J. Influence of gender on rates of hospitalization, hospital course, and hypercapnea in high-risk patients admitted for asthma: a 10-year retrospective study at Yale-New Haven Hospital. Chest. 2001;119(1):115-9. https://doi.org/10.1378/ chest.119.1.115

28. Jang $Y, Y o o H$. Gender differences of health behaviors and quality of life of Koreans with asthma. Open J Nurs. 2013:6(3):420-5. https:// doi.org/10.4236/ojn.2013.36057

29. Lisspers K, Ställberg B, Janson C, Johansson G, Svärdsudd K. Sexdifferences in quality of life and asthma control in Swedish asthma patients. J Asthma. 2013;50(10):1090-5. https://doi.org/10.3109/027 70903.2013 .834502
30. Correia de Sousa J, Pina A, Cruz AM, Quelhas A, Almada-Lobo F Cabrita J, et al. Asthma control, quality of life, and the role of patient enablement: a cross-sectional observational study. Prim Care Respir J. 2013;22(2):181-7. https://doi.org/10.4104/pcrj.2013.00037

31. Xu KY, Wisnivesky JP, Martynenko M, Mhango G, Busse PJ, Wolf MS, et al. Assessing the association of obesity and asthma morbidity in older adults. Ann Allergy Asthma Immunol. 2016;117(1):33-7. https://doi.org/10.1016/j.anai.2016.04.027

32. Temprano J, Mannino DM. The effect of sex on asthma control from the National Asthma Survey. J Allergy Clin Immunol. 2009;123(4):85460. https://doi.org/10.1016/j.jaci.2008.12.009

33. Cardoso MDL, D'Oliveira RAJ, Salame FM. Obesity and Quality of Life in Asthmatic Adult Patients in the Amazon Region. Am J Respir Crit Care Med. 2017;195:A7458.

34. Balzano G, Fuschillo S, Melillo G, Bonini S. Asthma and sex hormones. Allergy. 2001:56(1):13-20. https://doi.org/10.1034/j.13989995.2001.00128.x

35. Barros LL, Souza-Machado A, Corrêa LB, Santos JS, Cruz C, Leite $M$, et al. Obesity and poor asthma control in patients with severe asthma. J Asthma. 2011:48(2):171-6. https://doi.org/10.3109/02770 903.2011 .554940

36. Pelegrino NR, Faganello MM, Sanchez FF, Padovani CR, Godoy Id. Relationship between body mass index and asthma severity in adults. J Bras Pneumol. 2007;33(6):641-6. https://doi.org/10.1590/ S1806-37132007000600006

37. Dunn RM, Lehman E, Chinchilli VM, Martin RJ, Boushey HA

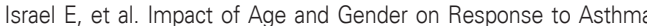
Therapy. Am J Respir Crit Care Med. 2015;192(5):551-8. https://doi. org/10.1164/rccm.201503-04260C

38. Boulet LP, Boulay MÈ. Asthma-related comorbidities. Expert Rev Respir Med. 2011;5(3):377-93. https://doi.org/10.1586/ers.11.34

39. Peters SP, Jones CA, Haselkorn T, Mink DR, Valacer DJ, Weiss ST. Real-world Evaluation of Asthma Control and Treatment (REACT): findings from a national Web-based survey. J Allergy Clin Immunol. 2007;119(6):1454-61. https://doi.org/10.1016/j.jaci.2007.03.022

40. Cazzola M, Calzetta L, Bettoncelli G, Novelli L, Cricelli C, Rogliani P. Asthma and comorbid medical illness. Eur Respir J. 2011;38(1):42-9 https://doi.org/10.1183/09031936.00140310 